\title{
Produção Agroecológica e Políticas Públicas no Assentamento Loiva Lourdes- Borebi-SP ${ }^{1}$
}

\author{
Andre Luiz de Souza ${ }^{2}$ \\ Maristela Simões do Carmo ${ }^{3}$
}

\section{Resumo:}

Este artigo é resultado do trabalho de conclusão do Curso de Especialização lato sensu Educação do Campo e Agroecologia na Agricultura Familiar e Camponesa, Residência Agrária. O estudo teve por objetivo analisar a visão de mundo sustentável proposta pela Agroecologia e sua evolução como um novo paradigma científico, bem como quais são as políticas públicas a ela associadas que estão sendo aplicadas no setor produtivo rural dos assentamentos de reforma agrária, em especial no Assentamento Loiva Lurdes em Borebi, Estado de São Paulo. A delimitação do estudo centra-se em como apreender as políticas públicas que tem aproximação com a Agroecologia, e como atingem os agricultores familiares, em particular aqueles mais desfavorecidos na escala sócio produtiva. Algumas linhas de crédito rural do Programa Nacional de Fortalecimento da Agricultura Familiar (PRONAF) tem como objetivo oferecer benefícios aos agricultores e familiares que adotam técnicas da produção de base ecológica. A Política Nacional de Agroecologia e Produção Orgânica (PNAPO), por sua vez, objetiva apoiar o processo de transição agroecológica, colaborando para que as agriculturas de bases ecológicas se tornem um meio propício aos agricultores dos assentamentos rurais. O Programa de Aquisição de Alimentos (PAA) apresenta incentivo à produção de alimentos nas unidades familiares e oferece garantias de compra da sua produção, sendo que em sua maioria os alimentos são repassados para abastecimento da merenda escolar. Como principal resultado observou-se que, para a efetividade das políticas públicas no Loiva Lurdes, é necessário melhorar o repasse de informações e diminuir a burocracia do processo.

Palavras-chave: Agricultura Familiar, Agroecologia, Políticas Públicas.

\section{INTRODUÇÃO}

Este artigo apresenta um esforço de pesquisa desenvolvido junto ao assentamento de famílias que desempenham atividades voltadas para a sustentabilidade, tendo como delimitação o tema da Agroecologia e das políticas públicas no assentamento rural Loiva Lurdes, Borebi, Estado de São Paulo.

\footnotetext{
${ }^{1}$ Artigo elaborado no curso de Educação do Campo e Agroecologia na Agricultura Familiar e Camponesa, Residência Agrária, da Faculdade de Engenharia Agrícola da Universidade Estadual de Campinas, financiado pelo PRONERA via CNPq.

${ }^{2}$ Licenciado e bacharelado em Ciências Sociais pela Universidade Estadual do Oeste do Paraná- Unioeste. Especialista em Educação do Campo e Agroecologia na Agricultura Familiar Camponesa-Residência AgráriaUniversidade Estadual de Campinas- Unicamp. Mestrando em Ciências Sociais na Universidade Estadual do Oeste Paraná - Unioeste/Campus Toledo- Pr.

${ }^{3}$ Profa Adjunta da Faculdade de Ciências Agronômicas (FCA)/UNESP-Botucatu e Prof ${ }^{\text {a }}$ Participante do Programa de Pós-Graduação da Faculdade de Engenharia Agrícola (FEAGRI)/UNICAMP, stella@ @ca.unesp.br e stella@agr.unicamp.br
} 
Apresentam-se conteúdos e tentativas sustentáveis, sendo que, nesse caso, é visivel o aumento de produção em áreas de assentamentos, levando à redução dos custos fixos médios e o aumento da produtividade física das culturas, oferecendo ao consumidor e ao produtor maior efetividade na produção de alimentos. A prática convencional, por sua vez, tem apresentado diversos problemas ambientais, como contaminação por fertilizantes químicos, agrotóxicos, erosão, causas estas que motivaram os questionamentos sobre a sustentabilidade das técnicas agrícolas da revolução verde em oferecer benefícios aos agroecossistemas.

Os principais obstáculos para a conservação da biodiversidade do agroecossistema tem menor importância quanto aos recursos biológicos, e apresentam insuficiência de conhecimentos sobre ecossistemas e espécies. Com a revolução verde foram inseridas técnicas impactantes na produtividade de alimentos, sem atender novas exigências sociais e tecnológicas, que deveriam ser implementadas para preservação do meio ambiente.

Porém, vários estudos científicos são direcionados para a resolução de problemas ambientais e incentivo de atividades com métodos agroecológicos, o que também beneficia a agricultura moderna no sentido de minimizar a emissão de poluentes industriais e a exploração não sustentável dos recursos naturais na atividade humana causando mudanças ambientais.

Abordam-se ainda os aspectos conceituais da Agroecologia, assunto que tem como intuito propor diferentes métodos pora os sistemas produtivos no campo, buscando alternativas sustentáveis em diversas regiões agrícolas. A Agroecologia contrapõe-se à agricultura agroquímica como um novo campo científico destinado a ampliar os conceitos e princípios da ecologia no manejo de sistemas de produção alimentar, assegurando a sua permanente sustentabilidade.

Também, foi pontuada a questão das várias interpretações e associações da Agroecologia que visam obter uma resposta do conhecimeto e o funcionamento das relações natureza homem, amparando-se nos princípios da ecologia, fundamentado na ciência que oferece metodologias de oportunidades para adaptação às mudanças do modo como é praticada a agricultura.

Em seguida, relatam-se as iniciativas agroecológicas que tem como embasamento as alternativas para desenvolver a agricultura familiar sustentável dentro dos processos do assentamento rural, possibilitando ganhos para sobrevivencia e redução dos impactos ambientais. As iniciativas expressam algumas controvérsias no que se refere às propostas da revolução verde, como a monocultura, a utilização de agrotóxicos, insumos artificiais, 
queimadas e o desmatamento. Nesse sentido, as políticas públicas são acionadas para possibilitar a qualificação profissional, o apoio técnico, financeiro e estrutural, ampliando o universo do campo, de forma que os assentamentos se tornem competitivos e autosustentáveis.

Entre as políticas públicas que oferecem contribuições para as famílias do assentamento estão o Programa de Aquisição de Alimentos (PAA) e o Programa de Fortalecimento da Agricultura Familiar (PRONAF). O PAA foi detectado como política que auxilia os assentados na comercialização mais segura dos seus produtos. Este programa comporta um Grupo Gestor, constituído pelos Ministério do Desenvolvimento Social e de Combate à Fome (MDS), Ministério da Fazenda (MF), Ministério do Planejamento, Orçamento e Gestão, Ministério da Agricultura, Pecuária e Abastecimento (MAPA), sobretudo através da CONAB - Companhia Nacional de Abastecimento e Ministério do Desenvolvimento Agrário (MDA), este último responsável por definir as medidas necessárias à execução do programa (sistemática de aquisição dos alimentos, regiões prioritárias, preços pagos segundo diferenças regionais, características da agricultura familiar e condições de doação e venda dos produtos).

O PRONAF, entre as suas linhas de atuação contempla a Agroecologia enquanto política pública, é destinado a promover a transição agroecológica de agricultores familiares, fator importante mediante o volume de crédito aportado pelo governo federal.

Apresenta-se, ainda, ao final, considerações quanto aos resultados obtidos, tendo como meta responder aos objetivos do estudo e problematizar os aspectos agroecológicos e as políticas públicas, mediante a realidade do assentamento em questão.

\section{METODOLOGIA}

Foi realizada uma pesquisa de campo envolvendo parte da população do Assentamento Loiva Lurdes, situado nos município de Agudos e Borebi, e administrado pelo Instituto Nacional de Colonização e Reforma Agrária - INCRA.

Ademais, como base qualitativa auxiliar de referência ao detalhamento dos lotes do assentamento, foram utilizados dados provenientes de levantamentos socioeconômicos realizados pela empresa prestadora de assistência técnica, Instituto Biosistêmico - IBS, no Loiva Lurdes, entre os meses de abril a outubro de 2013.

A metodologia específica deste estudo, do tipo exploratória descritiva, incluiu uma amostragem envolvendo seis (6) lotes de assentados do Assentamento Loiva Lurdes. Nestes 
lotes encontram-se agricultores em situações diversas de produção, organização social e renda, produzindo em bases ecológicas.

A coleta de dados foi efetivada tendo como instrumento de pesquisa um questionário semi estruturado, com perguntas relacionadas às práticas agroecológicas aplicadas e a utilização de políticas públicas em áreas do assentamento.

\section{A PRÁTICA CONVENCIONAL E AS EXPERIENCIAS SUSTENTÁVEIS}

No cultivo convencional, historicamente à base de fogo, arado e grade, sempre foi tentado "amansar" o solo, domá-lo e limpá-lo, no sentido de mantê-lo descoberto. As extensões de solos intensivamente aradas e gradeadas, sem vegetação diante do sol, do vento e da chuva, ficam expostas à força da erosão, que leva anualmente toneladas de solo, junto com a sua fertilidade. "Para contornar essa problemática foi implantado o sistema de plantio direto na palha, tendo como princípio básico, não revolver a terra" (SILVA, 2002, p. 55).

Apesar das divergências, há cientistas que afirmam que para cada tonelada de grãos produzida por métodos convencionais (aração e gradagens), no Brasil, dez toneladas de terra são carregadas pelas águas da chuva ou pelo vento. A prática convencional, oferece uma alta produção para a população se alimentar, mas persiste um enorme desconhecimento, por exemplo, a respeito do crescente uso de agrotóxicos. "O uso vem sendo adotado não apenas de modo indiscriminado, mas aplicado em doses cada vez maiores. Os agricultores foram persuadidos pelas indústrias e pelo comércio de agrotóxicos de que tais produtos são indispensáveis" (MATHEUS, 2002, p. 93).

Estudos realizados na área central do Brasil, que abrange Goiás, Mato Grosso e Mato Grosso do Sul, revelam que o uso de agrotóxicos é alarmante. “O milho e a soja já ocupam as áreas de recarga, o que exige 10 a 15 aplicações anuais de agrotóxicos. Já em regiões do Paraná a situação é menos perigosa, com o cultivo do milho" (TORRES, 2003, p. 95).

Segundo Koller et al. (2006), em grandes áreas da Região Sul do Brasil, onde a agricultura familiar é praticada e nas quais os pomares de citros raramente são superiores a três (3) hectares, constituindo a principal fonte de sustento dessas famílias, a aplicação da legislação contra o uso de agrotóxicos é difícil, pois não está prevista nenhuma forma de indenização ao agricultor, nem incentivos para o estabelecimento de culturas alternativas.

Os modernos métodos de cultivo do solo estão estreitamente ligados às conquistas e avanços da tecnologia, seja no aspecto do desenvolvimento da mecanização agrícola, ou de uso de produtos químicos para finalidades variadas. Conforme Souza (2004, p.52), "a 
mecanização do trabalho do homem, que passou do uso inicial da moderna pá e modesta enxada ao emprego de grandes mecanismos, desempenha um importante papel no controle às pragas e moléstias".

Os impactos da agricultura sobre o meio ambiente podem ser divididos em três grupos: locais - resulta dos efeitos diretos das práticas agrícolas sobre o ecossistema, e os efeitos incluem erosão, perda de solo, aumento de sedimentos em corpos hídricos e agroquímicos; regionais - são resultantes da intensificação dos efeitos das práticas agrícolas da região, incluindo a desertificação, poluição em larga escala de rios, lagos e estuários com pesticidas, sedimentos e dejetos animais, e globais - incluem mudanças climáticas e ciclos biogeoquímicos (TORRES, 2003, p. 37).

O homem é responsável pela conservação do solo. A natureza protege o solo até o momento em que o agricultor começa a cultivá-la. Posteriormente, dependendo do modo como ele faz o manejo do solo ocorre o desgaste e a erosão. A erosão produz valos e precipícios, causa queda de barreiras e pontes e estrago nas estradas, prejudicando outros setores da natureza e da economia (PEREIRA, 2003, p.424).

Assim, a maquinaria com suas múltiplas utilidades permite a economia de tempo e promete custos menores de produção. Portanto, todo o trabalho do homem auxiliado pela técnica moderna é uma consequência natural e direta da necessidade em se proceder cada vez mais uma agricultura mecanizada e química, pelas exigências sempre maiores de consumo do mundo moderno. Outra questão é que nos agroecossistemas convencionais a cadeia alimentar é severamente simplificada. E as práticas de preparo dos solos desenvolvidas pelo homem não existem na natureza.

A agricultura moderna, assentada em bases químicas, tem de ceder a uma agricultura de integração do agricultor para com o solo. Nesse sentido, “o problema da produção de alimentos, tem de ser colocado em bases diferentes das atuais, a partir de uma tomada de posição nova frente à terra, frente ao solo, base de toda e qualquer exploração agrícola" (SOUZA, 1988, p.121).

Por mais que venha a ser revolucionada a dinâmica da produção alimentar, a agricultura manterá a importância singular, até que surja nova alternativa à transformação biológica. Pois, a ação antrópica na agricultura é realizada com o propósito de transformar matéria-prima em produto, e regular as condições ambientais para obter maior produção de alimento a partir da dinâmica de transformações naturais. 
Cresce a consciência dos problemas resultantes do modelo agrícola atual e a necessidade de conciliar sistemas produtivos que conservem os recursos e favoreçam produtos mais saudáveis, sem comprometer os níveis de segurança alimentar já alcançados. É preciso analisar a produção de alimentos do ponto de vista ecológico (TORRES, 2003, p. 35).

$\mathrm{Na}$ visão ecológica o agricultor trabalha o solo, provocando modificações ambientais, porém, procurando um novo equilíbrio nos agroecossistemas. Isso ocorre devido às práticas agrícolas objetivarem um processo natural de sucessão ecológica. Na atualidade percebe-se que são raros os agricultores que planejam a forma de uso do solo em função do potencial das terras, sem gerar conflitos de cultivo, sem manejos inadequados, e sem o emprego de terras impróprias para cultivo.

Para a solução de possíveis problemas ambientais ao longo dos anos a agricultura evoluiu, adotando novas técnicas desenvolvidas por cientistas, e foram implantados novos métodos, novos produtos e instrumentos, bem como, máquinas para adubar, colher, semear, preparar o solo. A agricultura sustentável, sob o ponto de vista agroecológico, é aquela que, tendo como base uma compreensão holística dos agroecossistemas, seja capaz de atender, de maneira integrada, aos seguintes critérios:

“a) baixa dependência de inputs comerciais; b) uso de recursos renováveis localmente acessíveis; c) utilização dos impactos benéficos ou benignos do meio ambiente local; d) manutenção a longo prazo da capacidade produtiva; e) preservação da diversidade biológica e cultural; f) utilização do conhecimento e da cultura da população local; g) produção de mercadorias para o consumo interno e para a exportação" (ALTIERI, 2002, p. 5).

A manutenção e a melhoria das reservas de nitrogênio no solo, bem como o seu suprimento às plantas cultivadas, representam grandes desafios da agricultura orgânica (ALTIERI, 1996). A Agroecologia emerge com um sistema que garante a própria dinâmica da agricultura. Isso possibilita ao agricultor a autonomia de suas ações produtivas, deixando de ser subordinado pelas corporações do agronegócio. Essa característica da agricultura sustentável é que garantirá uma soberania ao agricultor, sem uso de adubos sintéticos e elementos geneticamente modificados.

\section{AGROECOLOGIA: ALGUNS ASPECTOS CONCEITUAIS}

A partir do início dos anos 1990, o Brasil é considerado o país com maior número de cursos de Agroecologia ou com enfoque agroecológico, tanto de nível médio, como de nível superior. 
Deste modo, mais rapidamente do que muitos esperavam, o paradigma agroecológico vem ganhando corpo e se fortalecendo por meio das redes de relações que se formam e cujos membros compartem alguns dos elementos epistemológicos que são o eixo central na ciência agroecológica (CAPORAL, 2009).

A fertilidade dos solos deve ser construída a partir de um amplo suprimento de matéria orgânica e, sobretudo na manutenção de elevados níveis de húmus, matéria orgânica já decomposta e estabilizada no solo, conforme teoria de Sir Albert Howard, elaborada na Índia de 1920 e considerada precursora da agricultura orgãnica (PENTEADO, 2000).

A base científica desta corrente de agricultura de base ecológica se assenta nas práticas de rotação de culturas, manejo e fertilização do solo. Assim como as correntes, natural e biodinâmica, o princípio gerador da estabilidade e saúde das plantas encontra-se no manejo da matéria orgânica como prática geradora de boas fertilidades e estruturação do solo (Albert apud EHLERS, 2000).

Além disso, como também nas outras correntes agroecológicas, o solo é considerado um "organismo complexo", repleto de seres vivos (minhocas, bactérias, fungos, formigas, cupins, etc), e de substâncias minerais em constante interação e interdependência, o que significa que ao se manejar um aspecto, adubação, por exemplo, faz-se necessário considerar todos os outros (diversidade biológica, qualidade das águas subterrâneas, suscetibilidade à erosão, etc), de forma conjunta. Este é o princípio da visão sistêmica da agricultura, também chamado holismo, a qual prescreve que a propriedade agrícola deva ser considerada em todas as suas dimensões (produtiva, ecológica, social, e econômica) (ODUM, 1988).

Por meio do equilíbrio entre as várias atividades, lavouras, criação de animais, uso de reservas naturais, entre outras, busca-se alcançar maior independência possível de energia e de materiais externos nas propriedades rurais. Este é o princípio da auto sustentabilidade, que vale para todos movimentos de agricultura de bases ecológicas.

Outra corrente tem como origem os pensamentos de Mokiti Okada (1882-1955), fundador da religião que originou a Igreja Messiânica e que propôs, em 1935, um sistema da produção que tomasse a natureza como modelo. Surgiu então, a forma de agricultura denominada Agricultura Natural (ODUM, 1988).

De acordo com Okada (1935), divulgado pela Associação de Agricultura Orgânica AAO (2003, p..32), "a harmonia e prosperidade entre os seres vivos são frutos da conservação do ambiente natural, a partir da obediência às leis da natureza”. 
Segundo o princípio da reciclagem e dos recursos naturais presentes nas propriedades rurais, o solo se torna mais fértil pela ação benéfica dos microorganismos (bactérias, fungos) que decompõem a matéria orgânica liberando nutrientes para as plantas.

As bases epistemológicas da Agroecologia mostram que, historicamente, a evolução da cultura humana pode ser explicada com referência ao meio ambiente, ao mesmo tempo em que a evolução do meio ambiente pode ser explicada com referência à cultura humana. Em outras palavras, os sistemas biológicos e sociais tem potencial agrícola.

Porém, este potencial foi captado pelos agricultores tradicionais por meio de tentativas, erros, aprendizados seletivos e culturais, que podem ser melhor entendidos na medida em que haja conhecimento formal, social e biológico, e ao verificar-se como as culturas tradicionais captaram este potencial. Portanto, o conhecimento formal, social e biológico, quando alcançado por meio do estudo dos sistemas agrários convencionais, adotando-se insumos desenvolvidos pelas ciências agrárias e com a experiência de instituições e tecnologias agrícolas ocidentais, podem se unir e desenvolver planos e estratégias para serem aplicados nos procedimentos envolvendo tanto os agroecossistemas tradicionais como os modernos (CAPORAL, 2009).

Assim, de modo geral é possível mencionar que, na década de 1980, o interesse da opinião pública pelas questões ambientais e a adesão de alguns pesquisadores ao movimento alternativo, sobretudo em função dos efeitos adversos dos métodos convencionais, tiveram alguns desdobramentos importantes no âmbito da ciência e da tecnologia.

É provável que uma das características mais marcantes destes desdobramentos tenha sido a busca de fundamentação científica para as suas propostas técnicas e, no caso da Agroecologia, o firme propósito de valorizar os aspectos sócio culturais da produção. Segundo Altieri (1996, p.11), "não basta abordar apenas os aspectos tecnológicos sem considerar as questões econômicas e sociais". A principal meta da Agroecologia é a resolução dos problemas da sustentabilidade como um todo.

O desenvolvimento sustentável não apresenta uma definição compatível para economistas cujo sinônimo de desenvolvimento seja apenas a variação o crescimento quantitativo do produto. $\mathrm{O}$ desenvolvimento sustentável encontra-se apoiado por uma busca comum, de uma melhor qualidade de vida para a população, apresentando preocupação com as gerações futuras (BRANDALISE e NAZZARI, 2012).

Nesse sentido, as preocupações com as políticas públicas devem ser voltadas aos aspectos agronômicos e sociais, com enfoque científico no estudo dos agroecossistemas que 
são, provavelmente, dado seu caráter endógeno, os subsídios que mais contribuíram para a rápida divulgação da Agroecologia.

\section{As Várias Interpretações e Associações da Agroecologia}

O presente estudo envolvendo as políticas públicas inseridas na prática com métodos da Agroecologia visa responder aos objetivos que consideram a Agroecologia como ciência, movimento social e sistema de produção (WEZEL, et al, 2009).

Em conformidade com a literatura a palavra Agroecologia é designada como implementação da ciência ecológica no estudo, concepção e gestão de agroecossistemas sustentáveis, constituindo uma ciência que trata as práticas desenvolvidas por meio da convergência de duas disciplinas científicas básicas: agronomia e ecologia (ALTIERI, 2002).

No entanto, desde os Encontros Brasileiros de Agricultura Alternativa (EBAAs), ocorridos nos anos 1980, houveram denúncias dos problemas ambientais decorrentes da produção convencional de alimentos, que passaram a ser vistos como fatores decorrentes do sistema econômico hegemônico no mundo, o capitalismo, incorporando de modo permanente os aspectos socioeconômicos, que juntamente com os aspectos ecológicos e técnicos passaram a compor a pauta do debate sobre a produção de alimentos em todo o mundo (PIANNA, 1999).

Para alguns estudiosos o termo Agroecologia deixa de ser compreendido como "uma disciplina científica que estuda os agroecossistemas; as relações ecológicas que ocorrem em um sistema de produção, para tornar-se mais uma prática de cultivo que permite abrigar várias tendências alternativas" (EHLERS, 2000, p. 28).

Penteado (2000), afirma que a Agroecologia com os aspectos ecológicos, tecnológicos e socioeconômicos, ao contrário do que aparentam, não é uma disciplina nova, mas um novo campo de estudos, que busca combinar as contribuições de diversas disciplinas: Agronomia, Sociologia Rural, Ecologia e Antropologia, entre outras.

Para outros autores a Agroecologia também corresponde a um campo de estudos que pretende o manejo ecológico dos recursos naturais, uma ação social coletiva de caráter participativo, um enfoque holístico e uma estratégia sistêmica. Isto para reconduzir o curso corrompido da coevolução social e ecológica, mediante um controle das forças produtivas que estanque seletivamente as formas degradantes e espoliadoras da natureza e da sociedade. Esta estratégia, se fortalece com a dimensão local, por ser portadora de um potencial endógeno, rico em recursos, conhecimentos e saberes que facilitam a implementação de estilos de 
agriculturas voltadas para a biodiversidade ecológica e diversidade sócio cultural (Guzmán; Molina, 1996, apud CAPORAL, 2009, p. 9).

O modo de produção com técnicas ecológicas inseridas na produção agroecológica tem como objetivo a maior viabilidade nos processos agrícolas naturais. Torna-se assim de fundamental importância trabalhar o solo com matéria orgânica, contribuindo na atividade biótica do solo. Para isso, são adotados os princípios básicos ecológicos que se fundamentam nas seguintes práticas: a reciclagem de nutrientes e retenção de energia, introdução de insumos internos, integração de culturas e pecuária, diversidade de espécies e recursos genéticos em agroecossistemas ao longo do tempo e espaço, com foco em interações e produtividade de todo o sistema agrícola.

A Agroecologia pode ser vista como um enfoque de alta densidade de conhecimento, com base em técnicas que não são impostas para desenvolver o conhecimento e experimentação dos agricultores (ALTIERI, 2002).

No contexto das práticas da propriedade rural, a Agroecologia pode ter vários significados: um novo modelo tecnológico, uma política pública, ou, em outros termos, definida como um movimento social.

No entendimento de Caporal (2009), Agroecologia tem enfoque científico, a qual é interpretada com significado amplo do termo e que favorece os processos de desenvolvimento rural com maior ênfase na sustentabilidade.

As práticas de Agroecologia têm como finalidade integrar os saberes históricos dos agricultores com os conhecimentos de diferentes ciências, proporcionando a análise do atual modelo de desenvolvimento aplicado nas atividades de agricultura, com abordagem sustentável (CAPORAL, 2009).

A prática agroecológica tem contribuído na constituição do corpus teórico e metodológico sendo definida como aplicação dos princípios e conceitos da ecologia no manejo e desenho de agroecossistemas mais sustentáveis. Isso defende uma nova "revolução modernizadora". Este processo tem como linha de pesquisa: "conhecimento local, incorporando o saber popular e buscando integrá-lo com o conhecimento científico, para dar lugar à construção e expansão de novos saberes socioambientais, com resultado no processo de transição agroecológica" (GUZMÁN CASADO et al.,2000, p.81).

Além disso, Agroecologia abrange a prática ecologicamente aplicada aos recursos naturais, constituindo-se de conhecimento científico que, partindo de um enfoque holístico e de uma abordagem sistêmica, pode contribuir para que as sociedades possam redirecionar o 
caminho alterado da evolução social e ecológica, em diferentes interrelações (CAPORAL, 2009).

Os elementos centrais da Agroecologia podem ser agrupados em três dimensões: ecológica e técnico agronômica; socioeconômica e cultural; e sócio política. Estas dimensões não são isoladas, se entrecruzam, influenciam umas às outras, de modo que é preciso estudálas, entendê-las e propor alternativas com abordagem inter, multi e transdisciplinar. Esta é a razão pela qual os agroecólogos aplicam ensinamentos da Física, Economia Ecológica, Ecologia Política, Agronomia, Ecologia, Educação e Comunicação, História, Antropologia e Sociologia, para os diferentes campos de conhecimento (GUZMÁN e OTTMANN, 2004; p. $5)$.

Em resumo, a Agroecologia, tem seu conceito com embasamento sistêmico, adota o agroecossistema como unidade fundamental de análise, traz a finalidade de proporcionar as bases científicas (princípios, conceitos e metodologias) necessárias para a prática de agriculturas mais sustentáveis, porém depende da implementação de novas políticas públicas.

Como sistema de produção constitui-se em um enfoque teórico e metodológico, sendo desenvolvido de modo interdisciplinar juntamente com disciplinas científicas, com o intuito de estudar a atividade agrária sob "uma perspectiva ecológica; uma disciplina específica, em que a Agroecologia se constitui num campo de estudo e pesquisa voltado para a sustentabilidade" (Altieri apud CAPORAL, 2009, p.7).

É neste sentido que a Agroecologia, tem como principal elemento a junção das diversas áreas do conhecimento, engendrando um sistema que perpassa a mera noção de produção de alimentos sem uso de agrotóxicos. Mas, garantindo uma ciclagem do meio ambiente como um todo, possibilitando pleno avanço na sustentabilidade ambiental e social das populações do campo e das cidades.

O desenvolvimento mais sustentável requer instrumentos que contribuam para a soberania alimentar do país. Diante disso, justifica-se a importância de desenvolver estudos com delimitação de pesquisa sobre "políticas e estratégias que estimulem a produção sustentável, a distribuição e o consumo de alimentos no sentido de atender o direito à alimentação de toda a população, respeitando as múltiplas características culturais e hábitos alimentares do povo" (CAPORAL, 2009, p. 17).

Para tanto, torna-se necessária a articulação de inúmeras formas de intervenção do Estado, associadas nas perspectivas de curto, médio e longo prazos A Agroecologia, como 
matriz disciplinar, está inserida no campo em que se identifica o pensamento de forma interdisciplinar, ou seja, “complexus, que significa tecido junto” (MORIN, 1999, p. 33).

Esta compreensão do termo Agroecologia, permeia novos valores de representações sociais nos espaços rurais, garantindo aos agricultores uma autonomia de participação e sociabilidades nas suas práticas agrícolas. A junção das práticas cientificas com valores tradicionais dos agricultores possibilita a introdução dos aspectos agroecológicos como um todo.

\section{ASPECTOS DAS POLÍTICAS PÚBLICAS}

A Política Nacional de Agroecologia e Produção Orgânica (PNAPO) objetiva apoiar o processo de transição agroecológica, colaborando para que a agricultura de base ecológica e orgânica se torne um meio de agricultores dos assentamentos obterem maior crescimento econômico e social (PNAPO, 2012).

A adoção de novas estratégias na política pública que oferecem maiores benefícios para o ambiente e para o homem, se depara com controvérsias devido tanto aos interesses da formulação e construção quanto da sua aplicação e operacionalização. Ademais, há a perspectiva dos atores que possuem origem nas diversas estruturas político ideológicas dos grupos sociais. O processo de construção da PNAPO deverá buscar possíveis soluções dos conflitos para a efetivação da implementação da política, considerando as diferentes articulações coexistentes em diferentes relações hierárquicas de poder, e entre as múltiplas instituições.

No caso da PNAPO, as instituições governamentais, impõem relações que reduzem o espaço de acesso em relação ao que pode ser alcançado pelos movimentos sociais, incluindo diferentes organizações. Os documentos dos seminários realizados pela Articulação nacional de Agroecologia (ANA) em conjunto com os movimentos sociais, mostram insatisfação com o Plano Nacional de Agroecologia e Produção Orgânica, pois o considera formado por muitas iniciativas desconectadas entre si, sem nenhuma coerência com as experiências acumuladas pela sociedade civil, além de ter abrangência e orçamento extremamente restritos (SIMONI, 2013, p. 8).

O descontentamento tem como interferência primordial o Estado, uma vez que apresenta falta de incentivo para implementação de práticas envolvendo a ciência e a pesquisa, assistência técnica e crédito rural, juntamente com a falta de políticas públicas para a agricultura. Ciência e Estado,com seus métodos e aplicações nos últimos 40 anos, deixaram 
transparecer a apropriação dos principais avanços científicos e tecnológicos realizada de forma ineficiente pelo mercado (MEDEIROS et al, 2002).

No processo de construção da PNAPO, a proposta do governo, em seu decreto apresenta diretriz para ampliar a geração de renda aos produtores por meio de acesso e desenvolvimento de mercados. Por outro lado, as organizações sociais propuseram, no processo de negociação, alterações para esta ampliação por meio da estruturação de um sistema de inspeção sanitária coerente com a produção artesanal garantindo o desenvolvimento de mercados com procedimentos de produção e práticas da Agroecologia (SIMONI, 2013).

Das críticas feitas à PNAPO, como a lei incentivadora de orgânicos, "se não for pensada de modo participativo - observando as fraquezas e potencialidades das atividades agroecológicas, tal política pode tornar-se mais um pacote tecnológico a ser instituído. Atualmente, a tecnocracia na moda é a do desenvolvimento sustentável, do gênero, do capital social. Amanhã, quem sabe não será a vez da agricultura orgânica? O tema muda, mas não a pedagogia, nem a abordagem tecnocrática...” (SABOURIN, 2009, p.14).

Em resumo, a problemática das politicas nos assentamentos está centrada na aceitação dos métodos participativos - muito enaltecidos na construção da PNAPO - "a relação entre os implementadores (técnicos, ONGs, representantes, cientistas,...; e os agricultores (quando envolve intenções e discursos) mostra-se relacionada nas questões de poder" (ALVES, 2008, p.28).

De acordo com Simoni (2013), atualmente o desenvolvimento rural exige novas estratégias para ampliar as metas de produtividade com diversidade nos produtos, oportunizando atividades produtivas que atendam as exigências da diversificação social. O que possibilita a valorização dos espaços rurais em que estão sendo inseridos os assentamentos, oferecendo novos significados para a atividade agrícola que traga resultados ao setor produtivo e ao espaço rural (KAGEYAMA, 2008).

A proposta do Programa Nacional de Fortalecimento da Agricultura Familiar, PRONAF Agroecologia, obriga o agricultor a apresentar um plano de transição rígido de três anos com indicações dos tipos de técnicas que irá abandonar. Porém, nota-se que é necessário flexibilizar os procedimentos para que o agricultor possa efetivamente usar o Programa com base na Agroecologia. Além de problemas de ajuste nas regras dessa modalidade de PRONAF, há inúmeros problemas na operacionalização do crédito para os agricultores familiares. É difícil montar um sistema baseado em planilhas em que os dados fornecidos 
pelos agricultores vão sendo alimentados, para em seguida se fazer uma análise de rentabilidade baseada em produtos. Essa normatização responde bem aos pacotes técnicos simplificados dos sistemas convencionais, mas com sistemas complexos e altamente diversificados ela não funciona (WEID, 2007, p.12).

O incentivo para ampliar a produtividade com práticas agroecológicas tem se expandido em grande escala para os agricultores, uma vez que as linhas do crédito rural do PRONAF, tem entre seus objetivos oferecer benefícios aos agricultores familiares que adotam técnicas da produção de base ecológica. Nesse caso, as garantias mais utilizadas são o penhor de safra, o aval, a adesão ao Seguro da Agricultura Familiar (Seaf), também conhecido como Proagro, além do penhor cedular e a alienação fiduciária do bem financiado. A definição da garantia é solicitada por meio de negociação entre o agricultor e o banco (GUADAGNIN, 2010, p. 20).

A contribuição do PRONAF, programa direcionado especificamente para os agricultores familiares, é acionado por meio de modalidades, conforme descreve Fuscaldi (2009, p.09).

“Compra Direta da Agricultura Familiar: possibilita a aquisição de alimentos pelo Governo Federal, a preços de referência, de produtores organizados em grupos formais (cooperativas e associações), inserindo os agricultores familiares no mercado de forma coerente, via compra direta de sua produção, garantindo a reserva estratégica de alimentos, sendo gerenciada pela Conab.

Compra para Doação Simultânea: tem como intuito promover a articulação entre a produção de agricultores familiares e as demandas locais de suplementação alimentar nutricional de escolas, creches, abrigos, albergues, asilos, hospitais públicos e outros, e dos programas sociais da localidade tais como bancos de alimentos, restaurantes populares e cozinhas comunitárias, resultando no desenvolvimento da economia local, no fortalecimento da agricultura familiar e na geração de trabalho e renda no campo, administrada pelos governos Estaduais, Municipais e pela Conab.

Formação de Estoque pela Agricultura Familiar: visa adquirir alimentos da safra vigente, próprios para consumo humano, oriundos de agricultores familiares organizados em grupos formais para formação de estoques, sob responsabilidade da Conab.

Incentivo à Produção e ao Consumo de Leite: tem como objetivo incentivar o consumo e a produção familiar de leite, com a finalidade de diminuir a vulnerabilidade social, 
combatendo a fome e a desnutrição, incentivando o fortalecimento do setor produtivo familiar, mediante a aquisição e distribuição de leite com garantia de preço.

Aquisição de Alimentos para Atendimento da Alimentação Escolar: com objetivo de promover a articulação entre a produção de agricultores familiares e as demandas das escolas para atendimento da alimentação escolar".

Para obter o benefício do financiamento o agricultor deverá ser avaliado e, mediante as informações técnicas da atividade que pretende investir, serão efetivadas análises das possibilidades de gerar renda suficiente para saldar as parcelas do empréstimo e ainda gerar receitas para a família. Nesse cálculo, o banco busca averiguar a viabilidade econômica do projeto, levando em consideração o valor do financiamento, a capacidade de produção da unidade familiar, e as despesas previstas e receitas esperadas com a venda da produção (GUADAGNIN, 2010).

Atualmente, a situação do financiamento da transição agroecológica por meio dos mecanismos do PRONAF depara-se com a falta de repasse de informação aos agricultores sobre as oportunidades e pouca capacidade das organizações de apoio ao acesso pelos agricultores (WEID, 2007).

Os agricultores familiares que contratam financiamentos no PRONAF demonstram grande empenho no cumprimento de seus compromissos com os bancos. O agricultor familiar faz planos e avalia sua atividade de forma permanente. A partir da análise de sua experiência anterior, a família estabelece projetos para o futuro. O extensionista rural é um auxiliar nas ações de planejamento. Nesse sentido, "apóia a família na avaliação do papel que o financiamento rural poderá cumprir na transição agroecológica. Para tanto, é importante que se considere o impacto das iniciativas financiadas sobre o conjunto do sistema produtivo" (GUADAGNIN, 2010, p. 20).

Destaca-se, neste questionamento, primeiramente que é necessário analisar o alcance do PRONAF Agroecologia enquanto política pública destinada a promover a transição agroecológica de agricultores familiares. Este alcance se apresenta necessário mediante o volume de crédito aportado pelo governo federal nas linhas de financiamento tradicionais nos últimos anos, restando para a transição agroecológica algo em torno de 0,01 \% (WEID, 2007).

O Programa de Aquisição de Alimentos - PAA - foi implementado com os objetivos de incentivar a produção de alimentos na agricultura familiar, assegurar a comercialização, contribuir para o acesso aos alimentos em quantidade, qualidade e regularidade pelas 
populações em situação de insegurança alimentar e nutricional e colaborar na formação de estoques (GRISA, 2009, p. 11).

$\mathrm{Na}$ esfera das Políticas Públicas nacionais foram implementadas medidas do PAA a partir da demanda de um conjunto de atores da sociedade civil e das próprias instituições estatais com intuito de reconhecer o fortalecimento da agricultura familiar, bem como oferecer benefícios aos projetos sobre a fome e segurança alimentar e nutricional. No ano de 2003 um conjunto de medidas e ações direcionadas à segurança alimentar e nutricional ganharam espaço na esfera pública, com a criação do Ministério Extraordinário de Segurança Alimentar (MESA), atual Ministério do Desenvolvimento Social e Combate à Fome (MDS), e o Programa Fome Zero.

$\mathrm{Na}$ sua estrutura organizacional, o PAA também comporta um Grupo Gestor, constituído pelo MDS, Ministério da Fazenda, Ministério do Planejamento, Orçamento e Gestão, Ministério da Agricultura, Pecuária e Abastecimento, por intermédio da CONAB, e MDA, responsável por definir as medidas necessárias à execução do programa, desde a aquisição dos alimentos até as condições de doação e venda dos produtos.

O controle social é atribuído à sociedade por meio das suas representações nos âmbitos nacional, estadual e municipal, no Conselho Nacional de Segurança Alimentar e Nutricional (CONSEA), no Conselho Nacional de Desenvolvimento Rural Sustentável (CONDRAF), nos Conselhos de Alimentação Escolar (CAE) e outros na esfera municipal (GRISA, 2009, p. 11).

Ainda o grupo conta com os "gestores executores" do Programa que são os estados, os municípios e a CONAB, e os "gestores locais" que são as organizações formadas pelos agricultores familiares com suas cooperativas, associações, sindicatos, etc, e entidades sócio assistenciais.

\section{RESULTADOS E DISCUSSÃO}

Os resultados apresentados são provenientes do levantamento de campo realizado com as famílias do assentamento Loiva Lurdes (Figura 1), em seis (6) lotes, e complementado com outras informações do INCRA e da prestadora de assistência técnica, Instituto Biossistêmico (IBS).

Segundo dados levantados dos participantes da pesquisa que residem nos seis lotes do assentamento, três famílias possuem uma área de 2ha para realizar sua produção, uma família tem 1,5ha, e outras 2 possuem uma área de 2,5ha para produção no sistema agroecológico. Eles informaram que os principais produtos cultivados (Tabela 1) são obtidos com práticas 
agroecológicas, sendo utilizado no cultivo o esterco, biofertilizante, palhada, e demais insumos que não possuem agrotóxicos nem produtos químicos.

Figura 1 - Vista Geral do Assentamento Loiva Lurdes, Municípios de Agudos e Borebi, Estado de São Paulo, 2015

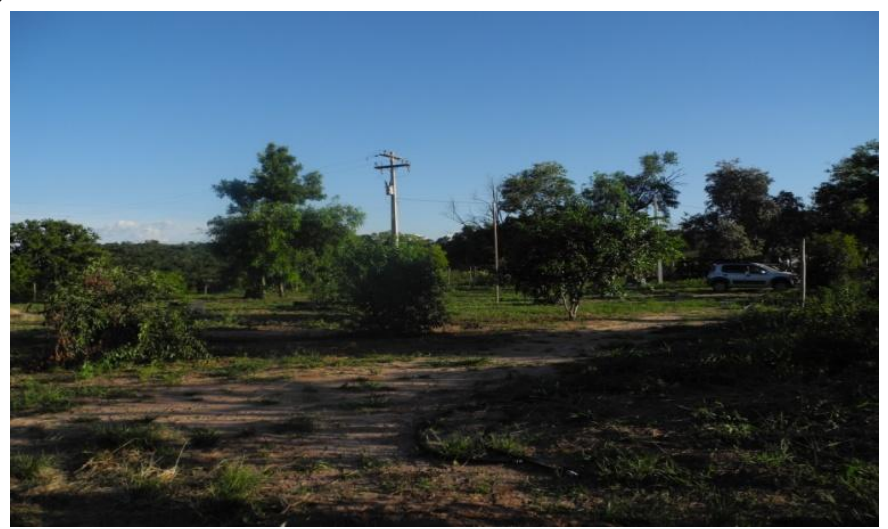

Fonte: Dados de pesquisa

Foto de Andre Luiz de Souza

As famílias assentadas, em geral, desenvolvem lavouras que se concentram na produção de hortaliças, grãos e frutas para o consumo e/ou venda em feiras e para o programa PAA (Figuras 2 e 3). Na opinião dos entrevistados o método de cultivo agoecológico (Figura 4) apresenta vantagens, uma vez que favorece os investimentos e também os recursos ambientais, como também apresenta maior oportunidade de comércio no mercado por se tratar de produtos com cultivo orgânico.

Tabela 1 - Produtos cultivados, Assentamento Loiva Lurdes, Municípios de Agudos e Borebi, Estado de São Paulo, 2015.

\begin{tabular}{llllll}
\hline lote 1 & Lote 2 & lote 3 & lote 4 & lote 5 & lote 6 \\
\hline Abóbora & Alface & Alface & Alface & Alface & Alface \\
Banana & Almeirão & Mandioca & Almeirão & Almeirão & Abobora \\
Rabanete & Jiló & Milho & Frutas & Frutas & Mandioca \\
Quiabo & Pimentão & Rabanete & Mandioca & Mandioca & Rabanete \\
& Quiabo & Quiabo & Quiabo & Milho & Quiabo \\
& & & Rabanete & \\
& & & & Quiabo & \\
\hline
\end{tabular}

Fonte: Dados da pesquisa

Figura 2 - Área de cultivo agoecológico das famílias amostradas, Assentamento Loiva Lurdes, Agudos e Borebi, Estado de São Paulo, 2015 


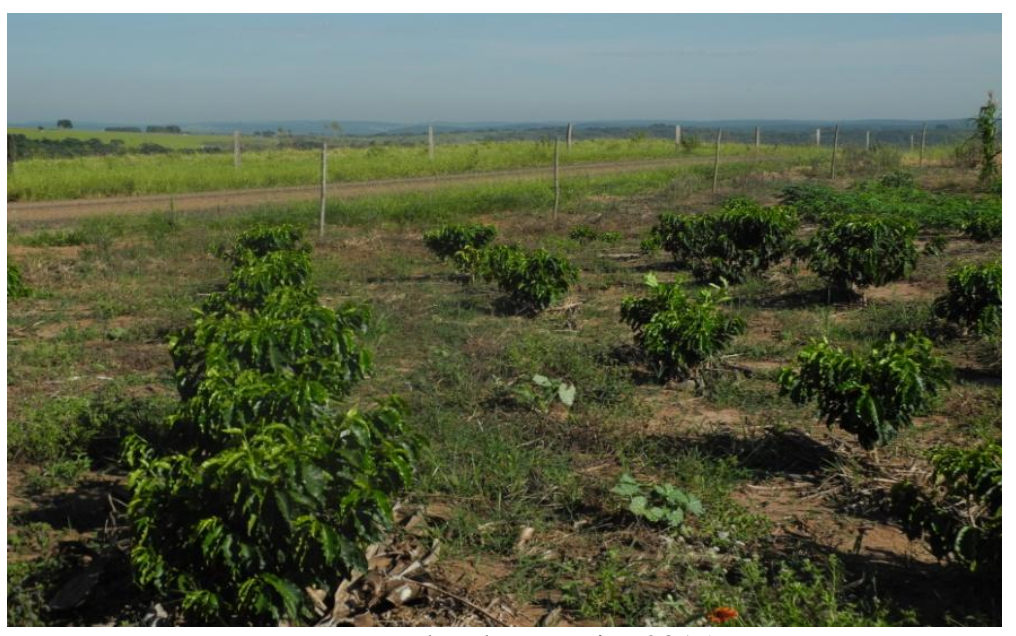

Fonte: Dados da pesquisa 2015.

Foto Andre de Luiz de Souza

Figura 3 - Práticas agroecológicas com o manejo de orgânico, Assentamento Loiva Lurdes, Agudos e Borebi, Estado de São Paulo, 2015

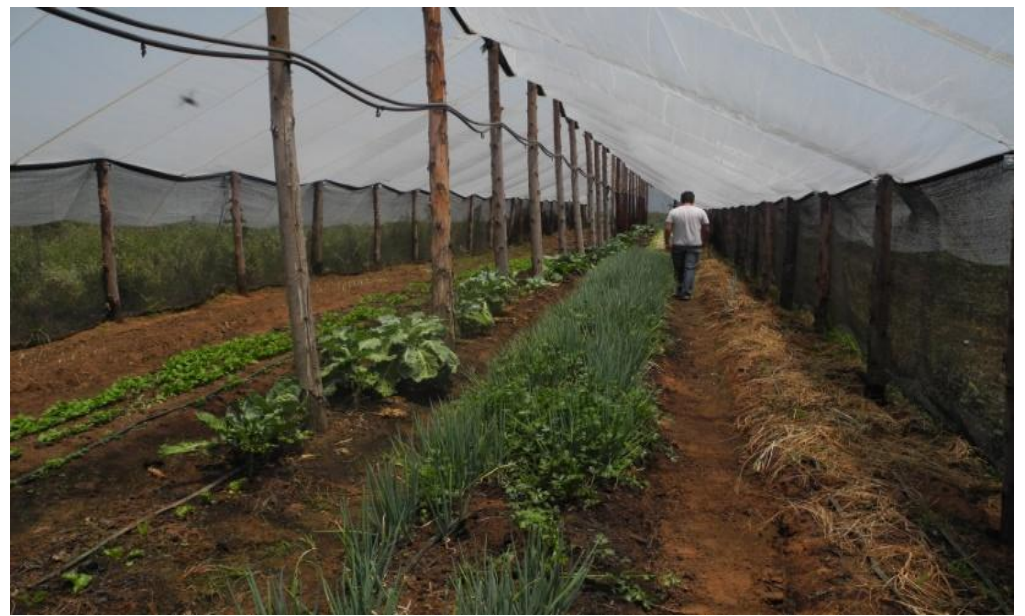

Fonte: Dados da pesquisa, 2015.

Foto de Andre Luiz de Souza

Figura 4 - Hortaliças comercializadas, Assentamento Loiva Lurdes, Municípios de Agudos e Borebi, Estado de São Paulo, 2015

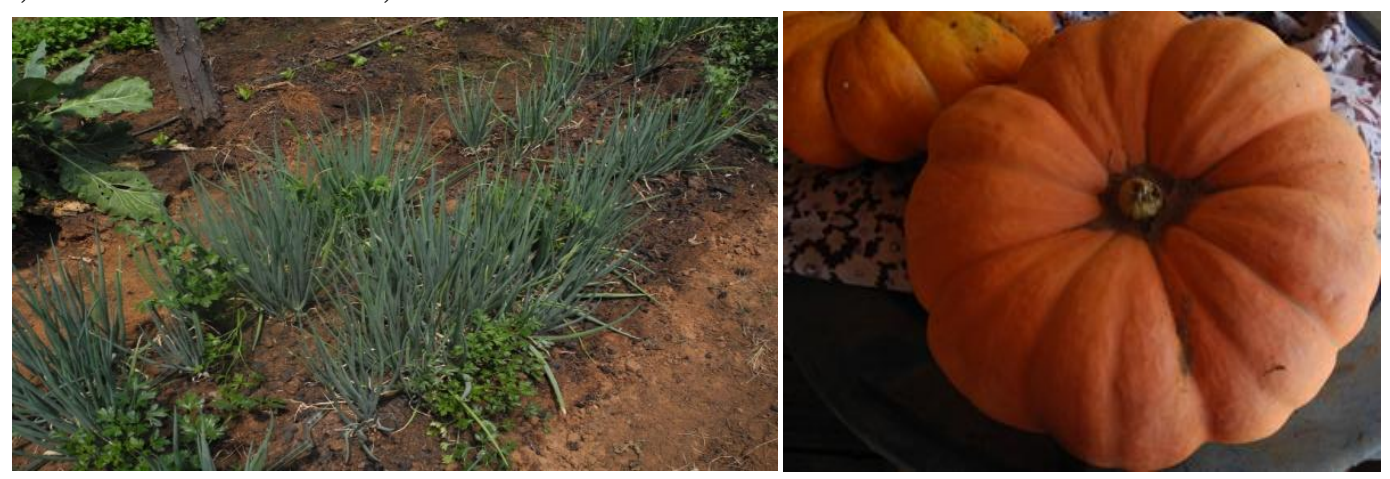

Fonte: Dados da pesquisa, 2015.

Foto de Andre Luiz de Souza 
A atividade hortícola, apesar de ter como entrave o acesso à água, tem ciclo rápido e legislação sanitária pouco exigente. Estes fatores vão ao encontro da necessidade de renda e capital de giro das famílias, bem como ao baixo nível técnico/tecnológico de produção dos assentados, principalmente na fase de instalação, como é o caso.

Dentre os principais problemas existentes para a produção de alimentos no assentamento destacam-se, além da questão da água, saneamento, manejo do solo, e falta de recursos financeiros.

O acesso à água para uso familiar ocorre de três formas: através de poços artesianos (03) instalados pelo INCRA em 2011, por meio de poços semi-artesianos construídos com créditos concedidos e/ou recursos próprios; e através de nascentes e minas (Gráfico 1).

Segundo os participantes da pesquisa $50 \%$ das famílias possuem disponibilidade de água insuficiente; 41,67\% consideram que é suficiente; 4,16\% destacaram que é abundante; e 4,16\% que ficam sem acesso a água.

Constatou-se que as famílias que tem os poços artesianos como único meio de acesso a água tem dificuldade para produzir. Segundo o INCRA os poços artesianos são construídos visando garantir água para uso doméstico. Parte das famílias utiliza desta água para produção, mas por vezes o fornecimento é suspenso devido aos problemas nos poços artesianos. Isto compromete muito a produção, sobretudo, nas estações secas.

Gráfico 1 - Disponibilidade de água, Assentamento Loiva Lurdes, Municípios de Agudos e Borebi, Estado de São Paulo, 2015

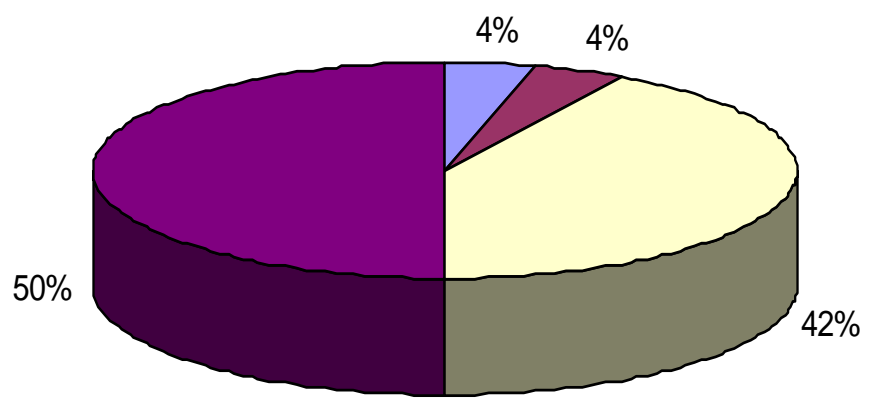

$\square$ Sem água $\square$ Abundante $\square$ Suficiente $\square$ Insuficiente

Fonte: Dados da pesquisa 
No que diz respeito a utilização de conhecimentos agroecológicos, o incentivo para os assentados partiu de outros agricultores, bem como de grupos do Movimento Sem Terra (MST), Associações e uma Organização Não Governamental (ONG), que fazem parte dos movimentos sociais em prol de comunidades dos assentamentos. O cultivo de hortaliças, com manejo orgânico envolve, segundo eles, um conjunto de princípios e atividades participativas entre esses grupos e a população da comunidade do assentamento, resultando na agricultura de base ecológica.

No assentamento as famílias utilizam equipamentos agrícolas (Figura 5) e fazem aplicação de insumos, em quantidade correta, sendo supervisionadas pela empresa prestadora de assistência técnica IBS, credenciada pelo Instituto Nacional de Colonização e Reforma Agrária (INCRA).

Figura 5 - Instalações e equipamentos para produção agrícola, Assentamento Loiva Lurdes, Municípios de Agudos e Borebi, Estado de São Paulo, 2015

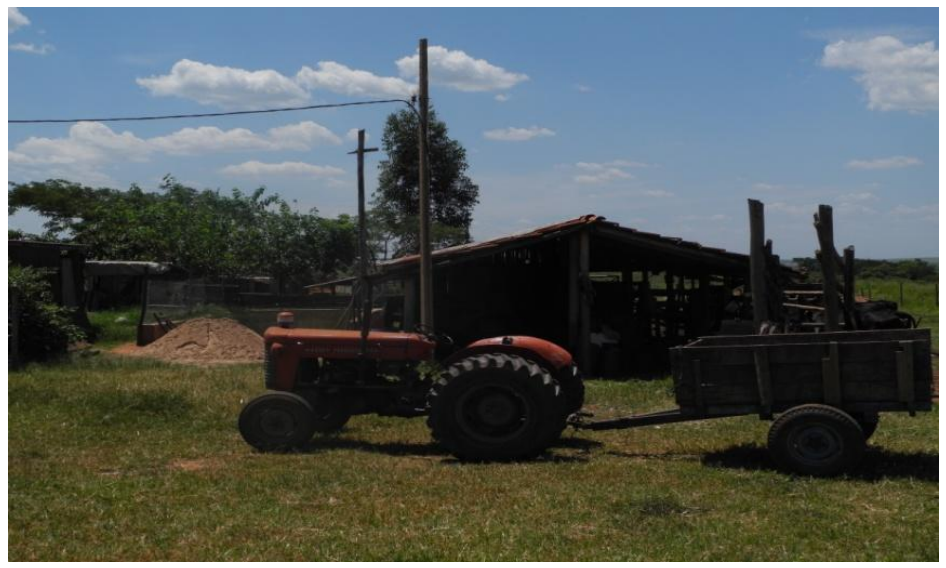

Fonte: Dados de pesquisa

Foto de Andre Luiz de Souza

As famílias do assentamento tem, ainda, entre suas principais cadeias produtivas a pecuária leiteira, e para tanto, possuem equipamentos adequados para manejo e armazenamento do leite até o destino final para consumo, demandando a pasteurização para o comércio no mercado institucional (Figura 6).

$\mathrm{O}$ assentamento possui espaço adequado com pastagens para o gado, e alimentação propícia em quantidade certa, pois a tendência é crescer a produção, tendo em vista que atualmente apresentam uma média diária de 23 litros de leite por lote, podendo aumentar instituindo negociações com laticínios que podem garantir a compra diária (Figura 7). 
AS atividades realizadas no assentamento são acompanhadas com a fiscalização de órgãos de sanidade, vigilância sanitária, Instituto Brasileiro do Meio Ambiente e dos Recursos Naturais Renováveis (IBAMA), dentre outros órgãos públicos, que repassam orientações para produção de alimentos orgânicos.

Figura 6.- Instalação para armazenamento do leite das famílias do Assentamento Loiva Lurdes, Agudos e Borebi, Estado de São Paulo, 2015

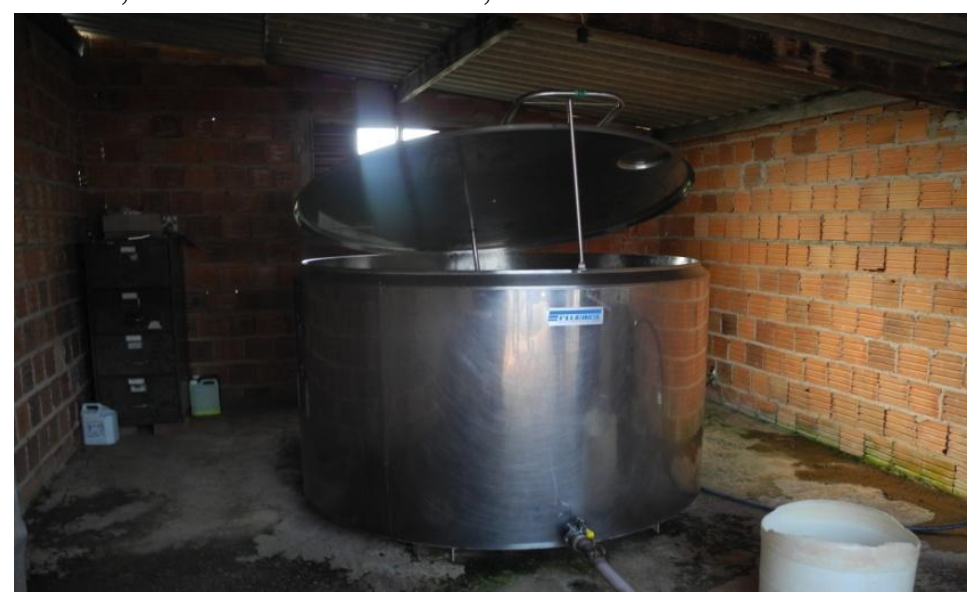

Fonte: Dados de pesquisa

Foto de Andre Luiz de Souza

Figura 7 - Área de lazer e matrizes leiteiras, Assentamento Loiva Lurdes, Agudos e Borebi, Estado de São Paulo, 2015

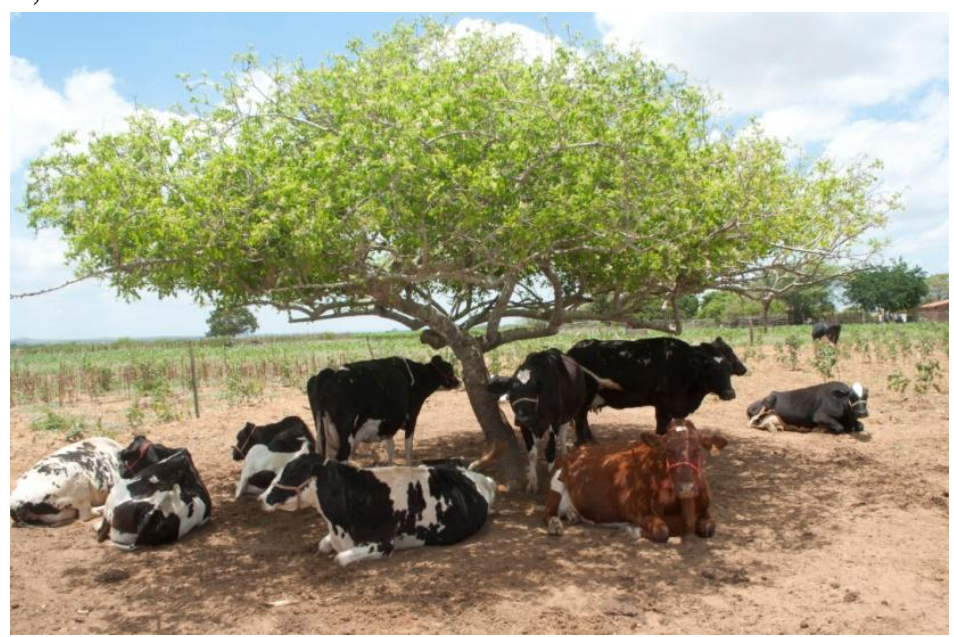

Fonte: Dados de pesquisa, 2015.

Foto de Andre Luiz de Souza

Quanto à colocação dos produtos nos mercados institucionais foram apontados pelos entrevistados que, cinco (5) deles realizam a comercialização de seus produtos por meio do Programa de Aquisição de Alimentos (PAA), e apenas um (1) faz a comercialização por meio de feiras. Os agricultores declararam que, dentre as desvantagens do PRONAF Agroecologia, 
encontra-se a exigência do banco, sendo que os assentados devem apresentar o laudo de processo de certificação orgânica, além do que, segundo eles, os juros são os mesmos das outras linhas do Programa (Gráfico 2).

Gráfico 2 - Colocação dos produtos, Assentamento Loiva Lurdes, Agudos e Borebi, Estado de São Paulo, 2015

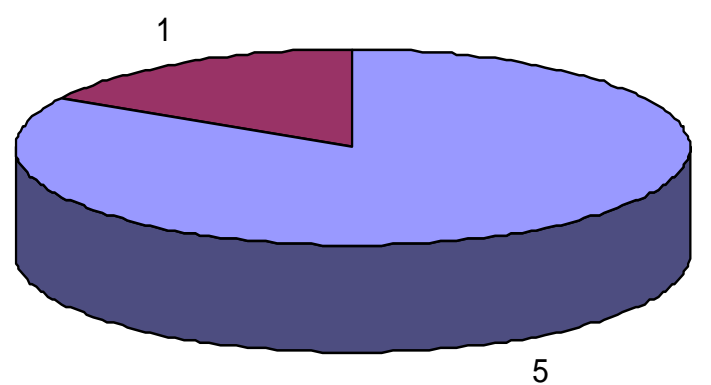

口PAA $\square$ Feira

Fonte: Dados da pesquisa

De acordo com o IBS, em pesquisa realizada em 2013, ao ser perguntado aos assentados em geral, qual o percentual de venda para o mercado institucional, foi obtido os porcentuais de $76,47 \%$ de colocação no PAA e $23,53 \%$ em outros mercados.

Complementando a pesquisa de campo, algumas informações revelaram que:

a) as seis (6) famílias apenas utilizam o emprego de mão de obra familiar, ou seja, não são contratadas pessoas para produção dos alimentos comercializados;

b) o nível de escolaridade dos participantes mostrou que dois (2) tem ensino médio completo, dois (2) enquadram-se no ensino fundamental séries finais e dois (2) no ensino fundamental séries iniciais;

c) a renda familiar dos assentados amostrados encontra-se na faixa entre $\mathrm{R} \$ 2.100,00$ a $1.000,00$, correspondentes a rendas anuais. Recebem em média $\mathrm{R} \$ 900,00$ a $\mathrm{R} \$ 300,00$ reais ao mês por venda de hortaliças cultivadas com práticas agroecológicas, sendo a maior parte desses produtos destinados ao Programa de Aquisição de Alimentos (PAA) e produzidos com os recursos do Programa de Fortalecimento da Agricultura Familiar (PRONAF). 


\section{CONSIDERAÇÕES FINAIS}

Com esta pesquisa pode-se concluir que, dos assentados amostrados no assentamento Loiva Lurdes, a visão de mundo sustentável proposta pela Agroecologia, e sua evolução como ciência que defende os aspectos ecológicos, pode ser auxiliada pela atuação e influência das políticas públicas aplicadas no setor produtivo com manejo orgânico. Neste contexto, o desenvolvimento sócio cultural nas áreas de reforma agrária, associado às fragilidades econômicas dos assentados em relação à produção agrícola, tem como princípio norteador a ruptura do atual modelo de agricultura.

Esses agricultores, com poucos recursos de terra e de capital, se destacam por utilizar uma forma de agricultura menos agressiva ao meio ambiente, o que promove a inclusão social e lhes proporciona melhores condições econômicas.

A experiência dos agricultores orgânicos, e sua relação com este sistema de cultivo, acaba levando a uma procura pela otimização da alocação de recursos para a produção.

A situação do financiamento da transição agroecológica no Loiva Lurdes, por meio dos mecanismos do PRONAF, depara-se com a falta de repasse de informação aos agricultores. Os assentados confirmam que, dentre as desvantagens do PRONAF, estão as exigências bancárias, obrigando-os a apresentar o laudo de processo de certificação orgânica. Essa burocratização das políticas públicas torna-se um entrave no desenvolvimento das práticas agroecológicas nas áreas de reforma agrária.

De um modo geral, as famílias da comunidade assentada no Loiva Lourdes, dentro da sua lógica familiar, concentram suas produções em lavouras e pecuária leiteira.

Porém, a renda obtida da agricultura não é suficiente para o sustento da família, pois não existem outros membros da família trabalhando fora, o que poderia contribuir para a melhoria da receita familiar. A renda mensal obtida por família é em torno de um a dois salários mínimos, o que comprova a necessidade de complementação com uma atividade não agrícola. Mesmo que as políticas públicas ofereçam incentivos e apoio técnico, os assentamentos ainda encontram-se com múltiplas dificuldades que dependem do apoio dos governantes.

As políticas públicas se destacam como eixo central para que os produtores tenham a conquista de ampliar o cultivo de produtos orgânicos, desde que existam mecanismos internos de controle que sigam os padrões da Agroecologia. Porém, são insuficientes no sustento dos agricultores, e por isso, muitas vezes a reforma agrária é criticada por seus opositores 
Os sistemas agroecológicos de produção dependem da viabilidade dos aspectos tecnológicos, mas também das questões políticas, econômicas e sociais.

Os aspectos tecnológicos tem como objetivo concretizar e edificar a proposta agroecológica para construir uma ruptura do atual modelo excludente de agricultura. Mas, não resulta apenas em esforços dos agricultores assentados em se desafiarem a romper de fato com o atual modelo de agricultura. Há necessidade de junção entre as políticas públicas e os setores da sociedade civil para construir a Agroecologia como protagonista do desenvolvimento rural sustentável.

Notou-se, no decorrer da realidade estudada, que os agricultores assentados tem convicção da produção agroecológica, mas muitas dificuldades surgem em trabalhar com essas práticas, mesmo em pequenas parcelas.

Em conclusão, pode-se afirmar que os projetos de reforma agrária, em especial o assentamento estudado, necessitam de um amplo investimento e maior acessibilidade das políticas públicas para alavancar a produção agroecológica e construir um espaço harmonioso e de qualidade de vida.

Igualmente, que possam dar uma estruturação econômica e social para os agricultores no intuito de fortalecimento e rompimento gradual com o modelo agroquímico hegemônico de agricultura, que visa apenas a produtividade em grande escala com a disseminação da monocultura. A diversidade, base dos princípios agroecológicos pode atuar na direção de um pleno desenvolvimento ambiental, social, cultural, político e econômico nas áreas de reforma agrária, possibilitando um novo rearranjo no quadro social dos assentamentos.

O estabelecimento dos mercados institucionais traz maior segurança na comercialização dos produtos dos assentados, mas outros mercados também devem ser estimulados, como as feiras de produtores, barateando o produto, uma vez que os colocam em contato direto com os consumidores.

O desenvolvimento sustentável, apoiado no enfoque da Agroecologia, perpassa os aparatos produtivistas do sistema atual da agricultura. Os procedimentos nos paradigmas agroecológicos constroem uma nova cultura no campo, resgatando os princípios tradicionais dos agricultores e forjando novos valores em relação ao meio rural, principalmente um novo olhar para o futuro e suas representações sociais como cidadãos participativos. 


\section{REFERÊNCIAS BIBLIOGRÁFICAS}

ALMEIDA, S. G; PETERSEN, P \& CORDEIRO. Crise sócioambiental e conversão ecológica da agricultura brasileira: subsídios à formação de diretrizes ambientais para o desenvolvimento agrícola. Rio de Janeiro: AS-PTA, 2001.

ALTIERI, M. A. Agroecologia: bases científicas para uma agricultura sustentável. Guaíba: Agropecuária, 2002, 592 p.

ALTIERI, M. Agroecologia: a dinâmica produtiva da agricultura sustentável. $1^{\circ}$ ed. Porto Alegre: Ed. Universidade /UFRGS, 1996.

ALVES, Adilson F. Do desenho à implementação de projetos de desenvolvimento rural sustentável: interfaces e negociações no Projeto Vida na Roça (PR). Florianópolis: UFSC, 2008. 234 p. (Tese de Doutorado em Ciências Humanas).

AUBERT, C. L'agriculture Biologique: pourquoi et comment la pratiquer. $4^{\circ}$. ed. Paris: Le Courrier du Livre, 1981. 377 p.

ASSOCIAÇÃO DE AGRICULTURA ORGÂNICA. Normas de Produção Orgânica, 2000.

BRANDALISE, T. NAZZARI, R. K. Políticas de sustentabilidade, responsabilidade social corporativas das questões ecológicas. Cascavel, PR. EDUNIOESTE, 2012.

CAPORAL, Francisco Roberto. Agroecologia: uma nova ciência para apoiar a transição a agriculturas mais sustentáveis. Brasília: 2009. 30p.; Agroecologia. 2.Desenvolvimento Rural Sustentável. 3. Segurança Alimentar e Nutricional I. Caporal, Francisco Roberto. CDU 631.588.9.

EHLERS, E. Agricultura alternativa: uma perspectiva histórica. Revista Brasileira de Agropecuária, ano 01, n.01, p.24-37, 2000.

FUSCALDI, Kelliane da Consolação. Programa de Aquisição de Alimentos: uma política de apoio à comercialização agrícola. Sociedade Brasileira de Economia, Administração e Sociologia Rural, Universidade de Brasília, Brasília - DF - Brasil.Campo Grande, 25 a 28 de julho de 2009. Disponível em: www.sober.org.br/palestra/15/139.pdf. Acesso em: jun. 2015.

GARCIA, M. A. C. da. Agricultura orgânica: uma agricultura sustentável. Jornal da Unicamp. Campinas, maio de 2001. ANO XV - N. 162.

GRISA, Catia. Desenvolvimento local, políticas públicas e meios de vida: uma análise do programa de aquisição de alimentos (PAA). Sociedade Brasileira de Economia, Administração e Sociologia Rural. Porto Alegre, 26 a 30 de julho de 2009. CPDA/UFRRJ, Rio de Janeiro, RJ - BRASIL. Grupo de Pesquisa: Políticas sociais para o campo. Disponível em: http://www.sober.org.br.palestra13/105. acesso em abril 2015.

GUADAGNIN, João Luiz. O crédito rural do Pronaf e a transição agroecológica: a visão governamental. Agriculturas, v. 7, n. 2, jul, 2010.

GUZMÁN CASADO, G.; GONZÁLEZ DE MOLINA, M.; SEVILLA GUZMÁN, E. (Coord.). Introducción a la agroecología como desarrollo rural sostenible. Madrid: Ediciones Mundi-Prensa, 2000.

KAGEYAMA, A. Desenvolvimento Rural: Conceitos e aplicações ao caso brasileiro. Porto Alegre: Editora da UFRGS. 2008. (Capítulo 1, p. 15-36; Capítulo 2, p. 51-84; Capítulo 3, p. 85-116).

KOLLER, Otto Carlos [et.al]. Controle químico do cancro cítrico em plantas jovens sob manejo convencional e orgânico. Ciência Rural, Santa Maria, v.36, n.4, p.1043-1048, jul- 
ago, 2006. ISSN 0103-8478. Disponível em: <http://www.scielo.br/pdf/cr/ v36n4 /a01v36n4.pdf. Acesso em: 12 jul. 2014

MATHEUS, C. Não sabemos o que comemos, 2002. In: TORRES, P. L. Uma leitura para os temas transversais: ensino fundamental. Curitiba: SENAR, 2003.

MEDEIROS, Josemar; WILKINSON, John; LIMA, Dalmo. O desenvolvimento científicotecnológico e a agricultura familiar. In: LIMA, Dalmo; WILKINSON, John. Inovação nas tradições da agricultura familiar. Brasília: CNPq/Paralelo 15, 2002.

MORIN, E. O método. Porto Alegre: Sulina, 1998.

MORIN, E. Por uma reforma do pensamento. In: Pena-Veja, A.; Nascimento, E. P. (Org.). O pensar complexo: Edgar Morin e a crise da modernidade. Rio de Janeiro: Garamond, 1999.

ODUM, E. P. Ecologia. Rio de Janeiro: Interamericana, 1988. 434p.

PENTEADO, S. R. Introdução à agricultura orgânica: normas e técnicas de cultivo. $2^{\mathrm{a}}$ ed. Campinas, Grafilmagem, 2000.

Pereira, S. B.; Pruski, F. F.; Silva, D. D.; Matos, A. T. Desprendimento e arraste do solo pelo escoamento superficial. Revista Brasileira Engenharia Agrícola e Ambiental, v.7, n.3, p.423-429, 2003

PIANNA, A. Agricultura orgânica: a subjacente construção de relações sociais e saberes. Dissertação de Mestrado. Rio de Janeiro: CPDA/UFRRJ, 1999.

PNAPO - Política Nacional de Agroecologia e Produção Orgânica, Presidência da República, Casa Civil, Subchefia para Assuntos Jurídicos. DECRETO N 7.794, DE 20 DE AGOSTO DE 2012. Brasília: Diário Oficial da União, 21.8.2012.

SABOURIN, Eric. Camponeses do Brasil entre troca mercantil e reciprocidade. Rio de Janeiro: Garamond, 2009. (Cap. 4).

SEVILLA GUZMÁN, E.; OTTMANN, G. Las dimensiones de la Agroecología. In: INSTITUTO DE SOCIOLOGÍA Y ESTUDIOS CAMPESINOS. Manual de olivicultura ecológica. Córdoba: Universidad de Córdoba, 2004. p. 11-26. (Proyecto Equal-Adaptagro).

SILVA, G. Geração do futuro. Plantio direto. (2002) Disponível em: <http://globorural.com/barra.asp?d=/edic/183/rep_plantiodireto.htm.>Acesso em: jul. 2014.

Souza, Maurício Novaes,Degradação e recuperação ambiental e desenvolvimento sustentável / Maurício Novaes Souza. - Viçosa: UFV,2004

SIMONI, Joana Cruz de. O processo de construção da política nacional de Agroecologia e produção orgânica (PNAPO): diálogos e disputas no caminho da transição. Reencontro de saberes territoriais Lationoamericanos, Perú, 2013.

TORRES, P. L. Uma leitura para os temas transversais: ensino fundamental. Curitiba: SENAR, 2003.

WEID, J. M. (ed) Caderno Financiamento da Transição Agroecológica. articulação nacional de Agroecologia - Grupo de trabalho Financiamento da Transição Agroecológica. Editor. Julho de 2007.

WEZEL, A. et al Agroecology as a science, a movement and a practice. A review. Agronomy for Sustainable Development, n.29, p. 503-515, INRA, França, 2009. 